\title{
Do Family Wishes Trump Verbal Advance Directive? An Ethics Case Report Amidst COVID-19
}

\author{
Sarosh Saleem ${ }^{1}$, Nuzhat Irfan Malik ${ }^{2}$, Nida Ilyas Shamsi ${ }^{2}$ \\ How to cite this article: Saleem S, Malik NI, Shamsi NI. Do family wishes trump verbal advance directive? an ethics \\ case report amidst covid-19. Ann Jinnah Sindh Med Uni 2020; 6(2):75-77
}

DOI: https://doi.org/10.46663/ajsmu.v6i2.75-77

\section{INTRODUCTION}

Covid 19 pandemic brought many challenges for public and healthcare workers. Healthcare workers all around the world are at the heart of this dreadful situation. While providing critical care to Covid 19 patients, they have faced many clinical as well as ethical dilemmas. The novelty and profound uncertainty associated with the clinical course of the disease introduced a dimension to the context of ethical dilemmas faced in clinical practice. The patients and families were being bombarded by information/misinformation from various forms of media. This, with the clinical uncertainty associated with the course of illness, led to widespread confusion and conflicts. We are reporting a case, managed by a team of experienced clinicians at a local tertiary care hospital, in which the patient's wishes conflicted with those of the family. The case was brought to the clinical ethics committee and Karachi Bioethics Group for discussion.

\section{The Case:}

A 54 years old paediatrician was admitted to a tertiary care hospital with severe Covid 19 in April 2020. More than ten days of intensive treatment failed to improve his oxygenation. High flow Oxygen and non-invasive ventilation were offered. He remained fully oriented during these ten days. Primary team consultants, along with anaesthetists, sought his permission for intubation and mechanical ventilation. In all his senses, his confident reply was: "Doctor, please don't intubate me! I will get better in the next two days." He was urged to sign the Do Not Intubate (DNI) form, as per his wishes, which he did not. His wife remained neutral throughout. Many of his colleagues called to keep a check on his well being. Two of his close friends, also physicians, earnestly advised him to opt for assisted ventilation.

1 Shalamar Medical and Dental College, Lahore, Pakistan 2 The Indus Hospital, Karachi, Pakistan

Correspondence: Dr Sarosh Saleem, Assistant Professor, Shalamar Medical and Dental College, Lahore, Pakistan

Email: sarosh.saleem@sihs.org.pk
On the morning of the 11th day of admission, the patient was confused, fatigued, and was progressively developing respiratory failure. His wife promptly met him and was distraught. She was counseled again, informed about the adverse outcome and the decision made by the patient about DNI. She insisted on providing assisted ventilation for him. After much ado, the clinical team started assisted ventilation. The patient suffered a fatal cardiac arrest after 16 hours.

The case prompts many questions about respecting the patient's wishes and the family's wishes. Physicians' prerogative and legal value of advanced directives represent matters of concern. The situation, nevertheless, created a degree of moral distress among healthcare providers. The key question is, whether it is ethically permissible to disregard patient's wishes and follow the wishes of the family? The purpose of this case report is to discuss all these aspects in light of principles of bioethics, socio-cultural and religious values, and legal rights.

\section{DISCUSSION}

\section{Patient's Autonomy:}

The values and social context of the patient and family are extremely important to be considered while executing decisions for critically ill patients. The patient, a paediatrician, had sound medical knowledge and we can reasonably assume that he was involved in discussions with his clinical team. He also understood the clinical significance of 'ventilation' or Assisted Life Support (ALS). With all his clinical acumen, in full consciousness, he asked his clinical team to "not intubate' him. It was an autonomous decision. This required the clinical team to respect the moral right of the patient to make his informed decision. Autonomy, a principle of Bioethics, has been described by Beauchamp and Childress as the right of individuals to express their values and choices about the medical care they receive. According to a Bioethicist, Mary B. Mahowald, the respect for the autonomy of a patient even outclasses the principles of beneficence and nonmaleficence, described by Beauchamp and Childress. 
In Pakistan, however, patients are generally not completely aware of their rights, and the consent is often not a truly 'informed' one. Although in this situation, the patient himself was a physician, he did not comply with a written advanced directive of Do Not Resuscitate (DNR) or Do Not Ventilate (DNV).

\section{Family's Wishes}

A family typically has a socially and culturally significant role in decision-making in Pakistan. The expressed wishes of family members, particularly, in situations where patients are incompetent to make decisions for themselves, are valued by clinical teams while making tough decisions. In this case, the patient's wife was communicating with the clinical team. As the patient's clinical condition deteriorated, she steadfastly insisted to 'do everything possible', including ventilation or ALS. The clinical team shared the wishes of the patient and discussed details of an anticipated dismal prognosis with her. Her stance remained steady. An empathetic response to her profound grief would need time and that has been one of the scarcities clinicians have been facing during this pandemic. An anxious spouse, startled by a sudden decline in her husband's condition and afraid of losing him to this scary illness, reacted in the most imaginable way. Covid 19 pandemic and the loss associated with it, has profoundly affected humans incredibly. She was certainly not prepared to let him go, as any family member would in such an unpredictable situation. The clinical team respected her wish.

\section{Clinicians' Dilemma}

The clinical team was caught in between the patient's directives, the family's wishes, and legal challenges. The clinical team reasonably believed that the patient would most likely not benefit from ALS. They also wanted to respect the choices determined by the patient himself, but lack of written documentation posed a risk of litigation. This is not an uncommon scenario in Pakistan, where legal documentation of advanced directives is not practiced. The uncertainty associated with the illness itself was enough to cast a shadow of doubt on the clinical judgments. In the earlier part of the pandemic, the clinical information and guidelines of Covid 19 infection were constantly being updated. The demise of the patient, just 16 hours after receiving ALS, supported the clinical judgment. It was not arbitrary to assume that the previously healthy patient, even though a physician himself, did not anticipate his illness to get worse so briskly. The clinical team, however, suffered from moral distress due to this situation. The fact that they had provided ALS 'against' the wishes of the patient consumed them considerably.
Some of the team members believed they caused more harm to the patient than benefit by providing ALS. They presented this case for discussion to the Clinical Ethics Committee.

\section{Role of the Clinical Ethics Committee}

The case not only highlights many ethical issues faced by clinicians but also underscores the key role of Clinical or Hospital Ethics committees. Clinical settings in Pakistan provide deficient support for such committees. There is a dearth of Clinical Ethics consultation. Inconsistent ethics education for clinicians frequently leads to moral distress. The prominent role of such committees is consultation and mediation in cases of conflict, such as the one discussed. Ethics consultants perform the role of mediators when stakes are high. Approaching such committees or consultants, if available, earlier in such situations may help mitigate some of the formidable challenges faced by clinicians. The committee reviews institutional as well as national policies, if any. These facilitate in bridging communication gaps inadvertently developed in such intensely emotional and critical situations with need to identify ethical dilemma and devise early decisionmaking strategies. The families equally benefit from such consultations. They frequently get appropriate answers and closure which helps them through their process of grief. In this case, the ethics committee, with the help of in-house team of psychologists, offered grief counseling to the family. The clinical team members also received support to mitigate moral distress.

\section{Recommendations}

Covid 19 has brought about a complex array of clinical as well as ethical challenges for the healthcare community around the world. The case under discussion may be approached from legal, social and, clinical perspectives. However, the lessons learned range from an individual to the policy level. Effective communication and adequate documentation of every discussion with the patients or families are crucial. Early decision-making should be tacitly encouraged among patients and their families. All autonomous decisions of critically ill patients should be shared with their immediate families and legally documented. The involvement of ethics experts or committees should be considered as early as possible. The institutions are responsible for developing and encouraging clinical ethics consultations. Reasonable policies should be implemented and disseminated by healthcare organizations. National resources should be adequately developed by promptly introducing formal clinical ethics education for all clinicians. 


\section{CONCLUSION}

The issue of the validity of a verbal advanced directive by the patient was called to attention when the patient lost the capacity and the wishes of his family conflicted. The clinical team was placed in a tight spot because they sincerely wanted to respect the wishes of the patient but were unable to do so. Against all odds, the clinicians provided the most competent care possible to the patient and respected family's wishes. In the end, the family lost a loved one, and the clinicians developed moral distress. Legal documentation and early recognition of an ethical dilemma are imperative for empathetic clinical care in particularly grueling times such as the Covid 19 pandemic. Development of clinical ethics consultation and national policies is obligatory for healthcare organizations and the state to provide quality clinical care.

Acknowledgements: We are thankful to Dr. Sohail Akhtar, Professor of Pulmonology, The Indus Hospital (TIH), Karachi and his team for bringing the case to the Clinical Ethics Committee, TIH. We appreciate the dedication and efforts of all our healthcare providers in this difficult time. We are obliged to our patients and their families, who are in our thoughts and prayers.

Authors' contribution: Dr. Sarosh Saleem Concive the idea, design, drafting, composition and review of the article. Dr. Nuzhat Irfan Malik Concept, design and critical review of the final version. Dr. Nida Ilyas Shamsi Concept, design and critical review of the final version

\section{References}

1. Humayun A, Fatima N, Naqqash S, Hussain S, Rasheed A, Imtiaz H, et al. Patients' perception and actual practice of informed consent, privacy and confidentiality in general medical outpatient departments of two tertiary care hospitals of Lahore. BMC Med Ethics. 2008; 9:14. doi: 10.1186/1472-6939-9-14.

2. Mahowald M. Bioethics and Women: Across the Life Span. New York, NY: Oxf Univ Press. 2006

3. Beauchamp T, Childress J. Principles of Biomedical Ethics. 7th ed. New York, NY: Oxf Univ Press. 2012.

4. Menzies RE, Menzies RG. Death anxiety in the time of COVID-19: theoretical explanations and clinical implications. Cogn Beha Therap. 2020;13(19): doi: 10. 1017/S1754470X20000215

5. Khan N. Advance Care Planning in Pakistan: Unexplored Frontiers. Asian Bioeth Rev. 2013;5(4):363-369.

6. Ali MM, Khokhar MA. Issues Regarding End-of-Life Care in Pakistan. J Palliat Care. 2019;35(3):174 -175. doi: $10.1177 / 0825859719855953$

7. Jafree S, Zakar R, Fischer F, Zakar M. Ethical violations in the clinical setting: the hidden curriculum learning experience of Pakistani nurses. BMC Med Ethics. 2015; 16:16. doi: 10.1186/s12910-015-0011-2.

8. Leuter C, Petrucci C, Caponnetto V, Cerra C, Lancia L. Need for ethics support in clinical practice and suggestion for an Ethics Consultation Service: views of Nurses and Physicians working in Italian Healthcare Institutions. Ann lst Super Sanita. 2018;54(2):117-125. doi: 10.4415/ANN_18_02_07.

9. Fiester A. Neglected Ends: Clinical Ethics Consultation and the Prospects for Closure. The Am J Bioeth. 2014;15(1):29-36. doi.org/ 10.1080/ 15265161. 2014. 974770 . 